\title{
Preparatory Test Anxiety: Cognitive, Emotionality, and Behavior Components
}

Eran Shadach, Itamar Levy-Frank, Sigal Levy, Tamar Amitai

The Academic College of Tel-Aviv Yaffo, Israel

\author{
Efrat Shadach \\ The Academic College for Society \\ and Arts, Israel
}

\begin{abstract}
Test anxiety interferes with the ability to communicate knowledge during tests. Preparatory test anxiety may lead to excessive learning that reduces concentration and leads to mistakes and ineffective learning. This preliminary study developed the Preparatory Test Anxiety Questionnaire (PTAQ), tested its reliability and construct validity, and assessed whether students with preparatory test anxiety exhibit excessive learning. Additionally, it explored the relations between the subscales and the total scores of the PTAQ and the TAI. Sample included 364 undergraduate college psychology students. Results indicated that the PTAQ is comprised of the 'cognition-emotion' and 'behavior' subscales and has an adequate internal consistency and construct validity. The subscales and total score of the PTAQ were positively correlated with those of the TAI. Regression analysis showed that the Emotion-Cognition scale of the PTAQ significantly added to the explained variance, while the Behavior scale did not. Results are discussed with regard to preparatory test anxiety.
\end{abstract}

Key words: test anxiety, preparatory, excessive learning, cognition, emotionality, behavior

Test anxiety interferes with one's ability to communicate what one knows (Austin \& Partridge, 1995; Putwain, 2008). It is a situationspecific trait (Hodapp, Glanzmann, \& Laux, 1995; Englert \& Bertrams, 2013) so some individuals tend to experience it more than others (Zeidner, 1998). Major components of test anxiety are worry and emotionality, or tenseness (Peleg, Deutch, \& Dan, 2016; Von der Embse, Kilgus, Segool, \& Putwain 2013). Common expressions include off-task behaviors (Montagano \& Bailey, 2011), social derogation, and cognitive obstruction (Von der Embse, Kilgus, Segool, \& Putwain 2013).

Correspondence concerning this article should be addressed to Eran Shadach, The Academic College of Tel-Aviv -Yaffo, 14 Rabenu Yeruham St., TelAviv -Yaffo, Israel, E-mail: eransh@mta.ac.il

Received March 1, 2017
Many students are anxious before a test (e.g., Dodeen, Abdelfattah, \& Alshumrani, 2014; see Stöber \& Pekrun, [2004] for a review) and some try to evade failure by working too hard and in a perfectionist manner (Martin, 2001; Martin \& Marsh, 2003; Martin, Marsh, \& Debus, 2001). Such 'active test anxiety' may include excessive learning, perceptions of low control, and unstable self-esteem (Martin, 2001; Martin et al., 2001), as well as the negative dimension of perfectionism (Arana \& Furlan, 2016).

Research on early test anxiety and resulting coping behaviors has provided mixed results. Test anxiety was negatively associated with academic performance (Ubaka, Sansgiry, \& Ukwe, 2015) and with self-regulated learning strategy (Ning \& Downing, 2015), but was positively associated with adaptive coping strategies (Kondo, 1997) and with proactive coping (Raffety, Smith, \& Ptacek, 1997). Additionally, worry and emotionality, major components of 
test anxiety, were positively associated with emotion-focused coping (Zeidner, 1996), and worry was negatively associated with problemfocused coping (Zeidner, 1996). On the other hand, both were positively associated with productive study behavior (Hodapp, 1991; Rost \& Schermer, 1997).

Some inconsistencies may be due to the use of existing measures of test anxiety, e.g., the Test Anxiety Inventory (TAI), and of coping strategies, e.g., the Differential Performance Anxiety Inventory (DAI) (Rost \& Schermer, 1997), or the adaptation of existing questionnaires (e.g., Stöber, 2004). Although beneficial in many ways, such measures may not be accurate in measuring early test anxiety and some specific active coping strategies.

\section{The Present Study}

The present study seeks to explore the relations between early, preparatory test anxiety, and excessive learning that exhausts the student, leads to reduced concentration and mistakes, and to a compensating exaggerated Learning. We offer a measure for assessing preparatory test anxiety and excessive learning that will help to identify students who otherwise may not be diagnosed. To the best of our knowledge, there is no such dedicated measure to date.

\section{Methods}

\section{Design}

This correlational research is a preliminary study aimed at developing the Preparatory Test Anxiety Questionnaire (PTAQ), and testing its reliability and construct validity. Subsequent aims were to test whether students with preparatory test anxiety exhibit excessive learning, and explore the relations between the subscales and the total scores of the PTAQ and the TAI.
Based on test anxiety literature, we expected a three-factor solution for the PTAQ that corresponds to the cognition, emotionality, and behavior components of test anxiety (American Psychiatric Association, 2013; Eum \& Rice, 2011; Hannon, 2012; Morris, Davis, \& Hutchings, 1981; Weiner \& Carton, 2012) and is therefore likely to be present in an earlier stage of preparatory test anxiety as well.

\section{Participants}

Participants were 365 first- and second-year undergraduate psychology students from a medium-sized Israeli college (63 male students and 302 female students). Age ranged between 20 and $58(M=24.7, S D=3.1)$. The inclusion criterion was to be a registered, regular student for the full three-year undergraduate psychology program. Researching samples of regular classes for studying test anxiety is customary (e.g., Peleg, Deutch, \& Dan, 2016; Piemontesi et al. 2012; Shadach \& Ganor-Miller, 2013), reflecting the view that test anxiety represents a continuum rather than an all-or-nothing phenomenon.

\section{Instruments}

Preparatory Test Anxiety Questionnaire (PTAQ). First, 24 self-reported items were generated to test the hypothesis that some individuals with test anxiety tend to experience it at a very early stage before the test and hence study ineffectively (Hagtvet \& Johnsen, 1992). Items were generated based on responses to a structured interview, delivered regularly over seven years by the clinical staff, to students applying for test anxiety treatment at a university clinical services facility. Responses that were repeatedly given to those items regarding students' feelings, thoughts, and behaviors preceding an examination were used to construct the PTAQ. Second, four clinical psycholo- 
gists familiar with test-anxiety patients graded each item for its relevancy on a scale of 1 (very low) to 5 (very high). The PTAQ comprises 15 self-reported items that were awarded a score of at least 4 by all four evaluators. These final 18 self-reported items comprise the PTAQ. Items $1,2,6,7,15$ comprise the emotionality sub-scale (e.g., "I begin to feel distress and inconvenience long before the test"); Items 3, 10, 11, 13, 16 comprise the cognition sub-scale (e.g., "Thoughts over low performance on the test trouble me long before the test"); Items 4, 8, 9, 17, 18 comprise the behavior sub-scale (e.g., "I tend to start studying for tests as soon as possible").

Participants in the present study were instructed to rate the extent to which each statement described their feelings, thoughts, and behaviors in the days and weeks before the examination, on a scale from 1 (does not describe me) to 4 (describes me very well).

Test Anxiety Inventory (TAI). The Test Anxiety Inventory (TAI) (Spielberger et al., 1980; adapted to Hebrew by Zeidner \& Nevo, 1993), is a widely used measure for test anxiety (Kavakci et al., 2014; Rus-Calafell, GutiérrezMaldonado, \& Masciullo, 2014; Stöber, 2004). It is a self-report questionnaire comprising twenty expressions or symptoms of anxiety in a test situation. Participants are asked to report the frequency of each symptom on a 4-point Likert-type scale ranging from 1 (never) to 4 (almost always).

The questionnaire comprises two subscales of eight items each. The subscales include a) a worry (cognitive) subscale, e.g., 'Thoughts of failure distract me from concentrating on the test question,' and b) the emotionality subscale, e.g., 'I am so stressed while taking a test, I have stomach cramps.'

Four additional items check for more general thoughts and feelings outside test situations. Ratings of all twenty items are used to determine a general test-anxiety score, ranging from
20 (low test anxiety) to 80 (high test anxiety). Furthermore, scores are calculated for each subscale, ranging from 8 (low worry/emotionality) to 32 (high worry/emotionality). The questionnaire was developed for self-assessment and can be utilized by individuals or groups.

\section{Procedure}

Participants were recruited in three incidental samples. Two samples were recruited during regular class (sample A: $n=106$, and sample $\mathrm{B}$ : $n=139$ ), and one sample was recruited via the official academic credit program (sample C: $n=$ 120). Study approval was obtained from the college's Institutional Review Board (IRB). Once informed consent was obtained, participants in samples $B$ and $C$ completed the study packet consisting of the TAI and the PTAQ in random order. Due to practical constraints, participants in sample $A$ were administered the PTAQ only. The directions for the PTAQ were to consider preparing for tests in general and not only for a specific test. Participants could quit at any time if they chose not to complete the process, there was no time limitation, and there was no monetary reward offered.

\section{Statistical Analysis}

Factor Analysis using Principal Axis Factoring with Promax rotation was used to detect the underlying PTAQ subscales. We used parallel analysis in order to test for $t$ significant eigenvalues, and Cronbach's Alpha to evaluate the resulting factors' reliability. Pearson correlation coefficients were used to measure the relation between the PTAQ and TAI subscales. Since we found that age and sex correlate with some PTAQ and TAI subscales, we used partial Pearson correlations to verify that these correlations remained significant when controlling for age and gender. 


\section{Results}

\section{Sample Comparison}

We tested samples A, B and C for differences in sex, age, and in all the scales of both questionnaires. The results of this comparison can be found in Table 1. We found that students from sample $\mathrm{C}$ were significantly younger compared to both other samples. Participants from sample A demonstrated less test anxiety than those from samples B and $\mathrm{C}$ in Total and Emotional-Cognition PTAQ scales. Participants from samples A and $\mathrm{C}$ showed less Behavior related anxiety than did participants from sample B. No differences were found between the samples is sex distribution or in the TAI scales.

Reliability and Construct Validity of the PTAQ

We used the PTAQ scores of all 365 participants to conduct Factor Analysis using Principal Axis Factoring with Promax rotation. The selection criteria for factors were eigenvalues greater than 1, and that the eigenvalue should be significant under parallel analysis. Items were assigned to the factor in which their loading was the largest, provided their loading within the factor exceeded 0.4. Bartlet's test of sphericity showed a significant result, $\left(\chi^{2}(91)=\right.$ 2068.4, $p<0.001$ ), supporting the hypothesis that the correlation matrix was factorable. KMO measure for sample size adequacy was .887 , indicating adequate sample size. Initially, the result of the factor analysis was a 3-factor solution in which item 11 (Long before the test is due I am thinking that it is necessary to organize the learning materials) was the only item assigned to factor \#3, with factor loadings of $.144, .109$ and .469 , respectively, on the 3 factors. Item 11 was therefore omitted from the questionnaire and we repeated the analysis with the remaining items. This resulted in two factors, accounting for $54.4 \%$ of the total variance. Parallel analysis supported the two-factor pattern. Pearson correlation between the two factors was 0.38 . The factor loadings are presented in Table 2.

Table 1 A comparison between the three samples comprising the study

\begin{tabular}{llllll}
\hline Sample & & $\mathrm{A}(N=106)$ & $\mathrm{B}(N=139)$ & $\mathrm{C}(N=120)$ & $F / \chi^{2}$ \\
\hline Age & & $25.5_{\mathrm{a}}(2.9)$ & $25.0_{\mathrm{a}}(2.7)$ & $23.5_{\mathrm{b}}(3.5)$ & $13.7^{* *}$ \\
Gender: & Female & $86(81 \%)$ & $113(81 \%)$ & $103(86 \%)$ & 1.2 \\
& Male & $20(19 \%)$ & $26(19 \%)$ & $17(14 \%)$ & \\
TAI: & Total & & $44.6(10.3)$ & $43.2(11.7)$ & 0.95 \\
Worry & & & $14.1(4.5)$ & $14.3(4.7)$ & 0.69 \\
Emotion & & & $21.3(5.5)$ & $20.7(5.7)$ & 0.14 \\
PTAQ: & Total & $2.0_{\mathrm{a}}(0.6)$ & $2.3_{\mathrm{b}}(0.6)$ & $2.2_{\mathrm{b}}(0.6)$ & $6.7^{* *}$ \\
Emotion-Cognition & & $1.8_{\mathrm{a}}(0.6)$ & $2.1_{\mathrm{b}}(0.7)$ & $2.1_{\mathrm{b}}(0.7)$ & $8.3^{* *}$ \\
Behavior & & $2.5_{\mathrm{a}}(0.7)$ & $2.7_{\mathrm{b}}(0.7)$ & $2.4_{\mathrm{a}}(0.7)$ & $4.9^{* *}$ \\
\hline
\end{tabular}

Note. TAI $=$ Test Anxiety Inventory, PTAQ $=$ Preparatory Test Anxiety Questionnaire Numbers are presented as $M(S D)$ or $N(\%)$. Groups with similar sub-indices do not differ significantly according to Tukey's test for multiple comparisons.

$* * p<.01$ 
Table 2 Component loadings for the (oblique) rotated two-factor solution

\begin{tabular}{|c|c|c|c|c|}
\hline Item & Component & Abbreviated item description & $\begin{array}{l}\text { Factor 1 } \\
\text { Preparatory TA } \\
\text { (Em-Cog) }\end{array}$ & $\begin{array}{l}\text { Factor } 2 \\
\text { Bev }\end{array}$ \\
\hline 1 & em & Distress and inconvenience before test & .83 & -.02 \\
\hline 27 & em & Worrying I will not succeed & .87 & -.01 \\
\hline 2 & em & Nervous and restless before test & .77 & .06 \\
\hline 23 & $\operatorname{cog}$ & Thoughts concerning abilities & .78 & -.07 \\
\hline 4 & $\operatorname{cog}$ & Low performance in the test & .71 & .03 \\
\hline 29 & $\operatorname{cog}$ & Try stop thinking about the test & .71 & .06 \\
\hline 7 & $\mathrm{em}$ & Stressed more than anybody & .50 & .26 \\
\hline 8 & em & Forget things I learned & .66 & .12 \\
\hline 15 & $\operatorname{cog}$ & Troubled by success of others & .60 & -.07 \\
\hline 5 & bev & Studying as soon as possible & -.10 & .70 \\
\hline 12 & bev & 'Digging in' on study materials & .05 & .50 \\
\hline 14 & bev & Need more time & .00 & .52 \\
\hline 31 & bev & Reading textbooks repeatedly & -.04 & .70 \\
\hline 33 & bev & Study more than others & .03 & .80 \\
\hline Eigenvalue & & & 5.96 & 2.05 \\
\hline
\end{tabular}

Following the results of the factor analysis, two subscales were computed, each one corresponding to a different factor. Each subscale was calculated as the mean of the items that had high loadings on its respective factor. Thus, the first subscale, named 'cognition-emotionality', was the mean of items 1, 2, 4, 7, 8, 15,23, 27,29 (range, 1.0-4.0, $M=1.98, S D=0.69$, Cronbach's alpha $=0.89$ ). The second subscale, named 'behavior', was the mean of items 5,12 , $14,31,33$ (range, $1.0-4.0, M=2.61, S D=0.71$ ) Cronbach's alpha $=0.78$ ). Table 2 presents the component loadings and eigenvalues for the (Promax) rotated two-factor solution. The overall total scale was computed as the mean of all items in the questionnaire (range, 1.07-4.00, $M=2.18, S D=0.59$ ), Cronbach's alpha $=0.87$. The results suggest that the two subscales and the total PTAQ have adequate internal consistency and construct validity.
In order to better understand the relations between excessive learning and test-anxiety, we first tested the correlations between the PTAQ and the TAI subscales, followed by a linear regression model that shows the predictive ability of the PTAQ scales.

\section{The Relations Between the PTAQ and the TAI}

In order to examine the relations between the PTAQ and the TAI, Pearson correlations were calculated between the subscales and the total scores of the two scales using only the data from the samples in which students filled out both questionnaires. Table 3 presents Pearson correlations between the PTAQ and the TAI, means, and standard deviations.

In order to test the extent to which PTAQ can predict test anxiety over TAI, we calculated a 
Table 3 Pearson correlations between PTAQ and TAI subscales

\begin{tabular}{lccc}
\hline & Total PTAQ & $\begin{array}{c}\text { PTAQ } \\
(\text { Em-Cog })\end{array}$ & $\begin{array}{c}\text { PTAQ } \\
\text { Behavior }\end{array}$ \\
\hline Total TAI & $.62^{* *}$ & $.71^{* *}$ & $.22^{*}$ \\
Emotional scale & $.62^{* *}$ & $.67 * *$ & $.27 * *$ \\
Worry scale & $.44 * *$ & $.55^{* *}$ & .07 \\
\hline
\end{tabular}

Note. TAI $=$ Test Anxiety Inventory, PTAQ $=$ Preparatory Test Anxiety Questionnaire, $\mathrm{Em}=$ emotion, $\operatorname{cog}=$ cognition, $* \mathrm{p}<.05 * * \mathrm{p}<.01$

Table 4 Standardized regression coefficient predicting the mean of four TAI items that are not included in the TAI subscales

\begin{tabular}{lclc}
\hline Predictor & Model 1 & Model 2 & Model 3 \\
\hline TAI-Worry & $.60^{* *}$ & $.53^{* *}$ & $.53^{* *}$ \\
TAI-Emotion & $.23^{* *}$ & $.20^{* *}$ & $.20^{* *}$ \\
PTAQ-Emotion-Cognition & & $.13^{*}$ & $.12^{\dagger}$ \\
PTAQ-Behavior & & & .02 \\
$\Delta \mathrm{R}^{2}$ & $.57^{* *}$ & $.01^{*}$ & .00 \\
\hline
\end{tabular}

Note. TAI $=$ Test Anxiety Inventory, PTAQ $=$ Preparatory Test Anxiety Questionnaire. ${ }^{\dagger} p=.053, * p<.05, * * p<.01$

test anxiety measure as the mean of the four TAI items that were not included in either one of the TAI subscales. This measure served as the predicted variable in a regression model, that included the TAI-Worry and TAI-Emotion subscales as predictors in the first block, PTAQ-Emotion-Cognition as the second block and PTAQ-Behavior as the third block. The results of this regression are presented in Table 4. We could see that the Emotion-Cognition scale of the PTAQ significantly added $1 \%$ to the explained variance, while the Behavior scale did not significantly contribute to the prediction.

When we repeated the analyses, both correlations and regressions, controlling for gender and age, the results were virtually equivalent.

\section{Discussion}

The first aim of this preliminary research was to develop a self-reported questionnaire for measuring preparatory test anxiety and excessive learning, and to test its reliability and construct validity. The components of cognition, emotionality, and behavior in test anxiety are well documented (e.g., American Psychiatric Association, 2013; Eum \& Rice, 2011; Morris, Davis, \& Hutchings, 1981; Schutz \& Davis, 2000). The findings that the PTAQ comprises a cognition-emotionality factor and a behavior factor are therefore in line with existing research and theory. The finding that the PTAQ has a single cognition-emotionality factor is in line with research that describes close in- 
teractions between cognitions and emotions (Ellis, 1962; Smith \& Lazarus, 1993). The current demonstration of excessive learning, although exploratory, adds to our understanding of the phenomenon of preparatory test anxiety and may alert us to a potentially developing test-anxiety.

The relations between the PATQ and the TAI should be interpreted with care, since low grades on the PTAQ may also represent anxious participants with an avoidant style. That said, there are significant correlations between the PTAQ's and the TAI's subscales and total scores, suggesting that the cognition-emotionality subscale of the PTAQ is a valid measure of preparatory test anxiety. The correlations between the cognition-emotionality subscale of the PTAQ on the one hand, and the emotionality and worry subscales of the TAI and the TAI total score on the other, suggest that for some students, anxious emotions and cognitions are already present days and even weeks before the test. The results also show a significant correlation between the behavior subscale of the PTAQ and the emotionality and total scales of the TAI, and a small to moderate correlation between the behavior subscale of the PTAQ and the worry subscale of the TAI. This pattern supports a relation between preparatory test anxiety and excessive learning that may result from it. The results of the regression analysis leave us with seemingly conflicting results. On the one hand, the relationship between the Emotional-Cognitive aspect of the PTAQ and test anxiety remains significant even when controlling for the TAI subscales. On the other hand, the Behavioral aspect loses its significance. We believe this to be a result of the specific nature of the measure we chose as an objective measure of test anxiety. The items composing it are part of the TAI, a questionnaire devised to measure the Emotional-Cognitive aspects of test anxiety and not behavioral ones. It is our opinion that these results emphasize the need for behavioral measures for testing test anxiety.

With regard to the presence of excessive learning at an early stage, avoidance, in this context academic procrastination, correlates positively with test anxiety (e.g., Elliot \& McGregor, 1999; Klingsieck, Grund, Schmid, \& Fries 2013; Putwain \& Symes, 2012). Therefore, the presence of excessive learning warrants an explanation. A full discussion is beyond the scope of this paper but shortly put, following Gray (1987), it is the expectation of not failing the test that over-motivates the student towards excessive learning (Hagtvet \& Johnsen 1992).

Research limitations include recruitment of three convenient samples. Additionally, several questions in the PTAQ were couched in terminology that is related to test anxiety (e.g., 'nervous'; 'distress') and may have artificially enhanced the correlation between the PTAQ and the TAI. Finally, since $80 \%$ of our sample were women (302 out of 365), caution should be taken when applying these results to male students. Future research should include augmentation of the excessive behavior subscale, and measuring it together with preparatory test anxiety against actual performance during a test.

Students with preparatory test anxiety and excessive learning could benefit from adequate interventions that would help them to improve their learning strategies (Birenbaum, 2007; Piemontesi, Heredia, Furlan, Sanchez-Rosas, \& Martinez, 2012). The present study may help to assess students' preparatory anxiety and excessive learning when anxiety levels are still building and may be effectively addressed (Cukrowicz, Smith, Hohmeister, \& Joiner Jr, 2009; Martin \& Marsh, 2006; Reavley \& Jorm, 2010), and may assist teachers and counselors in this regard (Ratanasiripong, Sverduk, Prince, \& Hayashino, 2012). 


\section{References}

American Psychiatric Association. (2013). Diagnostic and Statistical Manual of Mental Disorders (5 ed.). Arlington, VA: American Psychiatric Publishing.

Arana, F. G., \& Furlan, L. (2016). Groups of perfectionists, test anxiety, and pre-exam coping in Argentine students. Personality \& Individual Differences, 90, 169-173.

Austin, J. S., \& Partridge, E. (1995). Prevent school failure: Treatment test anxiety. Preventing School Failure, 40, 10-18.

Birenbaum, M. (2007). Assessment and instruction preferences and their relationship with test anxiety and learning strategies. Higher Education, 53, 749768.

Carver, C. S., Scheier, M. F., \& Weintraub, J. K. (1989). Assessing coping strategies: A theoretically based approach. Journal of Personality and Social Psychology, 56, 267-283.

Cukrowicz, K. C., Smith, P. N., Hohmeister, H. C., \& Joiner Jr., T. E. (2009). The moderation of an early intervention program for anxiety and depression by specific psychological symptoms. Journal of Clinical Psychology, 65, 337-351.

Dodeen, H. M., Abdelfattah, F., \& Alshumrani, S. (2014). Test-taking skills of secondary students: The relationship with motivation, attitudes, anxiety and attitudes towards tests. South African Journal of Education, 34, 1-18.

Ellis, A. (1962). Reason and emotion in psychotherapy. Secaucus, NJ: The Citadel press.

Elliot, A. J., \& McGregor, H. A. (1999) Test anxiety and the hierarchical model of approach and avoidance achievement motivation. Journal of Personality and Social Psychology, 76, 628-644.

Englert, C., \& Bertrams, A. (2013). The role of selfcontrol strength in the development of state anxiety in test situations. Psychological Reports: Disability \& Trauma, 112, 976-991.

Eum, K., \& Rice, K. G. (2011). Test anxiety, perfectionism, goal orientation, and academic performance. Anxiety, Stress \& Coping, 24, 167-178.

Hagtvet, K. A., \& Johnsen, T. B. (Eds.) (1992). Advances in test anxiety research, Vol. 7. Lisse, Netherlands: Swets \& Zeitlinger Publishers.

Hannon, B. (2012). Test anxiety and performanceavoidance goals explain gender differences in SAT-V, SAT-M, and overall SAT scores. Personality and Individual Differences, 53, 816-820.

Hodapp, V. (1991). Das Prüfungsängstlichkeitsinventar TAI-G: Eine erweiterte und modifizierte Version mit vier Komponenten [The Test Anxiety Inventory TAI-G: An extended and modified version with four components]. Zeitschrift für Pädagogische Psychologie, 5, 121-130.

Hodapp, V., Glanzmann, P. G., \& Laux, L. (1995). Theory and measurement of test anxiety as a situation specific trait. In C. D. Spielberger \& P. R. Vagg (Eds.), Test Anxiety: Theory, Assessment, and Treatment (pp. 47-58). Taylor \& Francis, Washington, DC.

Kavakci, O., Semiz, M., Kartal, A., Dikici, A., Kugu, N., \& Dusunen A. (2014). Test anxiety prevalence and related variables in the students who are going to take the university entrance examination. Journal of Psychiatry \& Neurological Sciences, 27, 301 307.

Klingsieck, K. B., Grund, A., Schmid, S., \& Fries, S. (2013). Why students procrastinate: A qualitative approach. Journal of College Student Development, 54, 397-412.

Kondo, D. S. (1997). Strategies for coping with test anxiety. Anxiety, Stress, \& Coping, 10, 203-215.

Martin, A. J. (2001). The Student Motivation Scale: A tool for measuring and enhancing motivation. Australian Journal of Guidance and Counselling, 11, 1-20.

Martin, A. J., \& Marsh, H. W. (2003). Fear of failure: Friend or foe? Australian Psychologist, 38, 31-38.

Martin, A. J., \& Marsh, H. W. (2006). Academic resilience and its psychological and educational correlates: A construct validity approach. Psychology in the Schools, 43, 267-282.

Martin, A. J., Marsh, H. W, \& Debus, R. L. (2001). A quadripolar need achievement representation of self handicapping and defensive pessimism. American Educational Research Journal, 38, 583-610.

Montagano, J. K., \& Bailey, R. N. (2011). Confirmatory factor analysis of the Children's Test Anxiety Scale. American Psychological Association convention presentation, Andrews University.

Morris, L. W., Davis, M. A., \& Hutchings, C. H. (1981). Cognitive and emotional components of anxiety: Literature review and a Revised Worry-Emotionality Scale. Journal of Educational Psychology, 73, 541-555.

Ning, H. K., \& Downing, K. (2015). A latent profile analysis of university students' self-regulated learning strategies. Studies in Higher Education, 40, 13281346.

Peleg, O., Deutch, C., \& Dan, O. (2016). Test anxiety among female college students and its relation to perceived parental academic expectations and differentiation of self. Learning \& Individual Differences, 49, 428-436. 
Piemontesi, S. E., Heredia, D. E., Furlan, L. A., SanchezRosas, J., \& Martinez, M. (2012). Test anxiety and coping styles with academic stress in university students. Anales de Psicologia, 28, 89-96.

Putwain, D. W. (2008). Test anxiety and GCSE performance: The effect of gender and socio-economic background. Educational Psychology in Practice, 24, 319-334.

Putwain, D. W., \& Symes, W. (2012). Achievement goals as mediators of the relationship between competence beliefs and test anxiety. British Journal of Educational Psychology, 82, 207-224.

Raffety, B. D., Smith, R. E., \& Ptacek, J. T. (1997). Facilitating and debilitating trait anxiety, situational anxiety, and coping with an anticipated stressor: A process analysis. Journal of Personality and Social Psychology, 72, 892-906.

Ratanasiripong, P., Sverduk, K., Prince, J., Hayashino, D., (2012). Biofeedback and counseling for stress and anxiety among college students. Journal of College Student Development, 53, 742-749.

Reavley, N., \& Jorm, A. F. (2010). Prevention and early intervention to improve mental health in higher education students: A review. Early Intervention in Psychiatry, 4, 132-142.

Rost, D. H., \& Schermer, F. J. (1997). Differentielles Leistungsangst Inventar (DAI): Handbuch [Differential Performance Anxiety Inventory: Manual]. Frankfurt/Main, Swets Test Services, Germany.

Rus-Calafell, M., Gutiérrez-Maldonado, J., \& Masciullo, M. (2014). Neuroticism and stimulus distance as determinants of test anxiety. Personality \& Individual Differences, Supplement, 60, S37-S37.

Schutz, P. A., \& Davis, H. A. (2000). Emotions and self-regulation during test taking. Educational Psychologist, 35, 243-256.

Shadach, E., \& Ganor-Miller, O. (2013). The role of perceived parental over-involvement in student test anxiety. European Journal of Psychology of Education, 28, 585-596.

Smith, C. A., \& Lazarus, R. (1993). Appraisal components, core relational theme, and the emotions. Cognition and Emotion, 7, 233-269.

Spielberger, C. D., Gonzalez, H. P., Taylor, C. J., Anton, W. D., Algaze, B., Ross, G. K. et al. (1980). Test Anxiety Inventory. Palo Alto, CA: Consulting Psychologists Press.

Stöber, J., \& Pekrun, R. (2004). Advances in test anxiety research. Anxiety, Stress, \& Coping, 17, 205 211.

Stöber, J. (2004). Dimensions of test anxiety: Relations to ways of coping with pre-exam anxiety and uncertainty. Anxiety, Stress, \& Coping, 17, 213-226.

Ubaka, C. M., Sansgiry, S. S., \& Ukwe, C. V. (2015). Cognitive determinants of academic performance in Nigerian pharmacy schools. American Journal of Pharmaceutical Education. 79, 1-8.

Von der Embse, N. P., Kilgus, S. P., Segool, N., \& Putwain, D. (2013). Identification and validation of a brief test anxiety screening tool. International Journal of School \& Educational Psychology, 1, 246-258.

Weiner, B. A., \& Carton, J. S. (2012). Avoidant coping: A mediator of maladaptive perfectionism and test anxiety. Personality and Individual Differences, 52, 632-636.

Zeidner, M. (1996). How do high school and college students cope with test situations? British Journal of Educational Psychology, 66, 115-128.

Zeidner, M. (1998). Test anxiety: The state of the art. New York, NY: Plenum.

Zeidner, M. \& Nevo, B. (1993). Test Anxiety Inventory (TAI): Development of the tool, its psychometric characteristics and some demographic and cognitive correlates. Megamot, 35, 293-306 [in Hebrew]. 